\title{
REPRESENTAÇÃO DISCURSIVA E SEQUÊNCIA ARGUMENTATIVA: DIMENSÕES DE UMA ANÁLISE TEXTUAL
}

\section{DISCURSIVE REPRESENTATION AND \\ ARGUMENTATIVE STRUCTURE: DIMENSIONS OF A TEXTUAL ANALYSIS}

Rosita Maria Bastos dos Santos*

Resumo: A análise textual, com enfoque para aquele desenvolvido no campo da Análise Textual dos Discursos, propõe que sejam observadas as questões de estruturação e organização textual, atentando para o caráter pragmático-comunicativo do texto. Este artigo apoia-se no princípio de que o propósito comunicativo, sobre o qual está pautada a argumentação, tem como objetivo obter de uma pessoa, ou auditório, adesão de um ponto de vista adotado (defendido) e expresso em uma alegação, na forma de tese. A construção argumentativa é examinada neste trabalho tendo como ponto de partida o fato de que a estrutura, tratada aqui a partir da noção de sequência argumentativa esta, necessariamente, associada à perspectiva discursiva. Para tanto, adotamos como fundamento teórico de base a proposta de Jean Michel Adam sobre análise textual dos discursos.

Palavras-chave: Texto argumentativo. Responsabilidade discursiva. Sequência argumentativa.

Abstract: Textual analysis, from the perspective developed in the field of Textual Discourse Analysis proposes that structuring issues and textual organization should be observed taking into consideration the pragmatic-communicative character of the text. This article is based on the principle that the communicative purpose, on which argumentation is guided, aims to get a person's or an auditorium's attention to an adopted perspective (defended) and expressed in a claim in the form of a thesis. The argumentative construction is examined in this article having as a starting point the fact that the structure, understood in this study from the notion of argumentative sequence, which is necessarily associated with the discursive perspective. This study adopted as a theoretical support Jean Michel Adam's proposal about textual discourse analysis.

KEYWORDs: Argumentative text. Discursive responsibility. Argumentative structure.

"Doutora. Universidade Estadual de Ponta Grossa - UEPG - ro.uepg@gmail.com 


\section{INTRODUÇÃO}

Este trabalho tem como objetivo central abordar aspectos argumentativos em textos de opinião e resultam de estudos ${ }^{1}$, que tiveram como aporte teórico alguns princípios apresentados por Jean-Michel Adam. Com apoio de Adam (2008), propomos a observação do texto dessa categoria, o de opinião, sob dois pontos abordados pelo autor: as noções de representação discursiva e de sequência argumentativa. Podemos dizer que a primeira questão, a representação discursiva, encontra-se nos domínios pragmáticos através dos quais se dá a configuração textual, enquanto que a segunda noção, a de sequência argumentativa, aponta para a estruturação/organização do texto.

Em sua obra, após revisão sobre o conceito de frase e período, Adam (2008, p. 104) considera que a gramática não fornece mecanismos suficientes para delimitar uma unidade textual. Para ele, enquanto o plano de delimitação for a gramática, não se obterá uma unidade de análise textual. Nessa linha de raciocínio, o autor nos mostra que "é sobre novas bases que propomos, hoje, articular uma linguística textual desvencilhada da gramática de texto e uma análise de discurso francesa (ADF)" (ADAM, p. 43). Isto porque, segundo o autor, a linguística textual passa a desempenhar papel de subdomínio da análise do discurso. $O$ recado talvez seja de que a linguística textual não prescinde dos

\footnotetext{
${ }^{1}$ As pesquisas com textos, constituintes de gêneros do argumentar, fizeram parte de projeto de pesquisa "Abordagem sobre estruturas e níveis de argumentação no texto escrito" desenvolvido na Universidade Estadual de Ponta Grossa por esta autora
}

aspectos e dos efeitos das situações de interação nos lugares sociais, nas línguas e nos gêneros que influenciam os enunciados. Adam (2008) estabelece, então, um modelo de Linguística Textual que tem como preocupação delimitar o campo de análise textual dos discursos.

Consideramos pertinente focar que o autor empenha-se em defender que um texto configura-se como unidade complexa e heterogênea. É bastante forte em sua tese a ideia de que o texto é constituído de sequências organizadas por operações de enlace entre o que é linguístico com o que é discursivo. A partir daí, a Adam apresenta um aporte teórico pautado na linguística textual e análise do discurso em que essas duas teorias convergem para uma análise textual dos discursos. À materialidade linguística se integram os efeitos advindos de condições socioculturais, políticas e históricas que em muito orientam a estruturação que se apresenta na organização textual. Por essa razão, o autor apresenta uma unidade de base para a análise textual, a proposição-enunciado, pois:

Temos necessidade, metalinguisticamente, de uma unidade textual mínima que marque a natureza do produto de uma enunciação (enunciado) e de acrescentar a isso a designação de uma microunidade sintático-semântica (a que o conceito de proposição atende, finalmente, bastante bem). (ADAM, 2008, p. 106. Grifo do autor).

Em nosso entendimento, ao incidir sobre um refinamento na delimitação de uma unidade mínima do texto, o autor visa justamente dizer-nos que: 
a) Qualquer análise de texto recobre análise de um ato de enunciação.

b) Não existe enunciado isolado.

c) Um texto deve "ser observado como um conjunto de atos ou de comportamentos" (p. 107)

Elencando uma unidade mínima de análise textual aponta-se para o fato de que na organização de enunciados há, também, uma organização enunciativa. Nesse sentido, consideramos pertinente destacar o que o autor nos mostra a respeito da noção de texto: um composto de unidades interligadas (já que não existe enunciado isolado) e:

Em grande parte, determinada pelo que chamaremos de orientação argumentativa (ORarg) do enunciado. As três dimensões complementares de toda proposição enunciada são: uma dimensão enunciativa $[B]$ que se encarrega da representação construída verbalmente de um conteúdo referencial [A] e dá-lhe uma certa potencialidade argumentativa [ORarg] que lhe confere uma força ou valor ilocucucionário $[\mathrm{F}]$ mais ou menos identificável. (ADAM, 2008, p. 109. Grifos do autor)

Assim, partimos da noção de que o texto deve ser tratado como conjunto de atos enunciativos entre proposições-enunciados organizadas hierarquicamente (níveis ascendentemente mais complexos) ${ }^{2}$ em estruturas entre as quais se encontra a sequência textual

\footnotetext{
${ }^{2}$ Dadas entre os segmentos: palavras-signos, proposições enunciadas, frases e/ou versos, períodos e/ou sequências, parágrafos ou estrofes e partes de um plano de texto associados por operações textualizadoras capazes de garantir o princípio da continuidade (processos de ligação). (ADAM, 2008)
}

(aqui tratada, com mais especificidade, a argumentativa). Os dois aspectos aqui abordados são "alocados", na teoria de Adam, em espaços diferentes (um configuracional e um estrutural). Pautamo-nos no princípio, como aponta o autor, de que o caráter estruturante do texto motiva-se pelo o que ele chama de força centrífuga, ou seja, a influência dos dados externos à constituição do texto.

A partir da análise de um grupo de vinte textos, de caráter argumentativo (textos de opinião escritos, de ampla circulação em mídias escritas.), propôs-se observar o comportamento da argumentação tendo como aporte teórico a proposta da ATD, sob dois aspectos principais: a perspectiva enunciativa e a perspectiva da organização estrutural do texto, numa concordância a respeito do fato de que, na constituição textual o estrutural não prescinde do discursivo.

\section{Propondo UMA ANÁLISE TEXTUAL DOS DISCURSOS}

Para Adam (1992, 2008), o texto merece ser tratado como ato linguístico socialmente organizado. Em suas obras, sustenta que há a necessidade de uma proposta de análise textual dos discursos em que os elementos textuais se relacionam entre si construindo relações de sentido (o que difere de uma relação de sucessividade apenas, como já pensado em outras fases da Linguística Textual (LT)).

A Análise Textual dos Discursos - ATD terá o papel de conciliar duas linhas teóricas que, embora tenham se desenvolvido independentemente, oferecem, de seus planos 
próprios de análise e metodologia, princípios que podem ser articuladas para uma análise textual dos discursos. Assim, um dos fundamentos básicos para Jean-Michel Adam (2008) em sua proposta teórica será considerar, tanto para uma definição de objeto (o texto) como para um empreendimento metodológico de análise deste objeto, que a Linguística Textual e a Análise do Discurso se articulam. A ideia é que dessas duas linhas teóricas possam ser fornecidas condições para dar ao texto um tratamento condizente com a organização sequencial que, por sua vez, será inseparável da organização configuracional-pragmática, já que são "dois princípios tão complementares quanto repetição, ligação e segmentação”. (ADAM, 2010, p. 10. Grifos do autor).

Tendo por base tal especificação, Adam (2008) afirma que o texto não se dissocia do discurso por compreender que à materialidade linguística se integram os efeitos advindos de condições socioculturais, políticas e históricas que em muito orientam a estruturação que se apresenta na organização textual. A partir daí, o esforço do autor é demonstrar quais aportes teóricos tanto da Linguística Textual (LT) quanto da Análise do Discurso (AD) podem compor a análise textual dos discursos (ATD). Por isso, na sua visão, será necessário considerar que:

Postulando, ao mesmo tempo, uma separação e uma complementaridade das tarefas e dos objetos da linguística textual e da análise do discurso, definimos a linguística textual como um subdomínio do campo mais vasto da análise das práticas discursivas. (ADAM, 2008, p. 43).
Fica claro que são da LT as funções de descrever as formas de articulação e os mecanismos de organização da textualidade e a ela cabe o papel, na análise de discurso, de teorizar e descrever os encadeamentos de enunciados elementares no âmbito da unidade de grande complexidade que constitui um texto (ADAM, 2008). Numa relação com essa perspectiva é que Adam organiza a ATD em níveis de análise textual. Como apresentado em Passeggi (2010), os principais níveis de análise propostos por Adam para uma ATD podem ser assim resumidos:

a) Um nível sequencial-composicional, correspondente à própria estruturação linear do texto;

b) Um nível enunciativo, baseado na noção de responsabilidade enunciativa (PdV);

c) Um nível semântico, apoiado na noção de representação discursiva $(\mathrm{Rd})$;

d) Um nível argumentativo correspondente aos atos de discurso realizados no texto e que exprimem uma orientação argumentativa (Oarg).

Esses níveis são organizados na teoria da ATD em duas dimensões: a dimensão sequencial (correspondente ao item a) e a dimensão configuracional ou pragmática (correspondente aos itens b, c ed). Cada uma das dimensões tem participação na textualização e é descrita na teoria de Adam por seus elementos constituintes além da forma como se organizam na composição de unidades mais complexas.

A textualização, que sustenta um discurso materialmente falando, se deve aos componentes inerentes à situação de produção 
que lhe é externa, porém, pertinente. Forças internas ao texto (campo teórico da LT) e forças externas a ele (práticas discursivas) são reguladoras na constituição estrutural do texto e ambas devem ser consideradas como bases para uma análise textual. Adam (2010, p. 97), fazendo referência ao fato de que texto e contexto são campos em associação diz que:

[...] todo texto é, por definição, um campo de forças centrífugas (dados externos que vão da intertextualidade às condições materiais e sócio-históricas de produção, passando pela identidade do orador encenada na enunciação e nas escolhas relativas ao gênero) e de forças centrípetas que garantem a unidade do texto e sua dinâmica interna. (ADAM, 2008, p. 97. Grifos do autor)

Com o objetivo de associar à análise do texto os efeitos de uma perspectiva discursiva (que atua tanto para a formação quanto para a depreensão de sentidos), Adam considera justificável (e necessário) pensar em uma teoria de "produção co(n)textual de sentido, que deve fundar-se na análise de textos concretos". (ADAM, 2008,p.23).

Metodologicamente, o autor elege o estudo das regularidades pertinentes ao campo da análise textual (por conseguinte da LT), mas sempre salienta que é preciso reconhecer que o texto não pode deixar de estabelecer conexão com o contexto em que foi produzido. Seria o mesmo que dizer que palavras, enunciados, sequências não se apresentam numa relação com elas mesmas. Tais componentes estão "significando" porque se submetem a processos de textualização perpassados por um discurso que os sustenta. Assim, o preceito de texto como todo organizado de sentido só poderá ocorrer tendo em vista o leitor/ouvinte para o qual se projeta ações de textualidade.

Ao descrever o campo de trabalho da LT, Adam justifica o estabelecimento de um campo de análise (textual) responsável pela descrição e pela definição das diferentes unidades textuais bem como das operações em todos os níveis de complexidade realizadas sobre os enunciados e, dessa forma, a textualização se constitui como um processo a partir do qual o texto se estabelece como unidade de sentido, pois segundo o autor:

É contra essa visão fixista da textualidade que trabalha a análise textual dos discursos, questionando as próprias fronteiras da textualidade (peritextualidade) e a ideia de um exterior (contexto) que se oporia ao seu interior (fechamento estrutural). (ADAM, 2008, p. 73)

Adam (1992, 2008) considera que a constituição do texto deve ser compreendida por sua complexidade e heterogeneidade e admite que os vários planos acionados no processo de textualização, lembrando que dois campos agem nessa organização: o textual e o discursivo.

\section{A REPRESENTAÇÃO DISCURSIVA}

Uma proposição-enunciado está associada a um valor enunciativo que leva a certa interpretação. A responsabilidade enunciativa que caracteriza esta dimensão corresponde ao ponto de vista (PdV) a partir do qual damos conta das possíveis interpretações. $E$ 
aqui que encontramos os sinais ou as marcas através das quais o locutor se posiciona em relação ao conteúdo referencial $[\mathrm{A}]^{3}$.

É da relação entre a proposição enunciada [A] (um dito) com um ponto de vista [B] (um dizer) que derivam os valores argumentativos [ $\left.\mathrm{C}_{1}\right]$ e os atos ilocucionários [C2] dos enunciados. O esquema a seguir ${ }^{4}$ representa a relação entre as três dimensões complementares de toda proposição enunciada e é apresentado por Adam (2008) como forma de resumir sua a discussão a respeito da construção de uma proposição-enunciado. Eis o esquema sobre o valor enunciativo subjacente ao enunciado:

Figura 1 - esquema da representação de proposição-enunciado como microunidade enunciativa

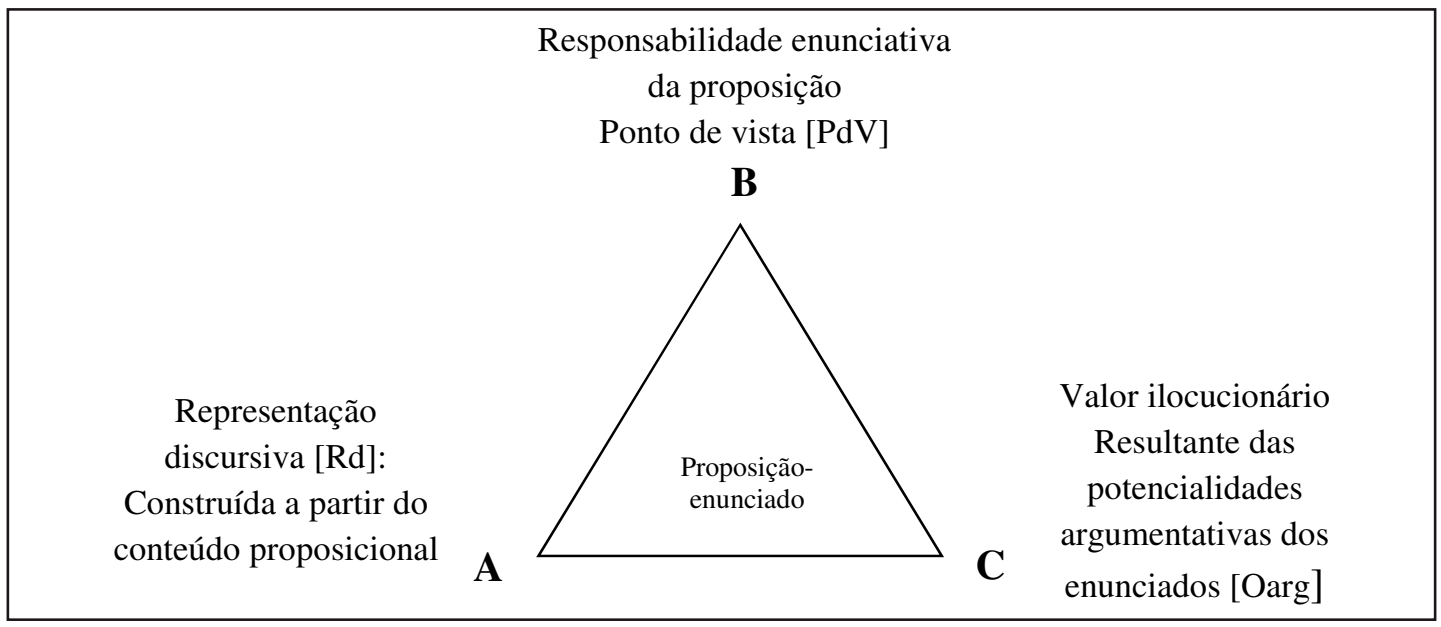

Fonte: ADAM, 2008, p. 111.

${ }^{3}$ Assim como o autor, salientamos que a disposição dos elementos não representa nenhuma hierarquia. A disposição assim apresentada situa $[\mathrm{A}]$ e $[\mathrm{C}]$ na mesma linha correspondendo à codificação da pragmática para os atos do discurso, pois para todo enunciado [A] há uma força ilocucionária [C], mediados pela enunciação [B].

${ }^{4} \mathrm{~A}$ seguir, apresentamos o texto que nos permitirá ilustrar um pouco dos princípios teóricos apontados por Jean-Michel Adam.

\footnotetext{
${ }^{3}$ Seguimos, aqui, as convenções propostas por Adam.

${ }^{4}$ A edição consultada para este trabalho apresenta uma inconsistência entre o texto explicativo do autor e a re-
}

\section{A SEQUÊNCIA ARGUMENTATIVA}

A fim de tratarmos o texto como conjunto de ações advindas dos processamentos discursivos e estruturantes, transitamos, agora, por uma camada de natureza organizacional: a unidade chamada sequência textual. 
Quando Adam (192, 2008) demonstra o processo argumentativo, ele retoma o modelo de Toulmin (2006) e acrescenta um lugar para a contra-argumentação. Tanto o modelo original quanto a complementação de Adam representam uma célula argumentativa, a saber:

Figura 2 - Esquema da sequência argumentativa baseado em Adam (2008)

\begin{tabular}{|c|c|c|c|c|c|c|}
\hline $\begin{array}{l}\text { Tese } \\
\text { anterior } \\
\text { P.arg.0 }\end{array}$ & + & $\begin{array}{l}\text { Dados } \\
\text { Fatos } \\
\text { P.arg.1 }\end{array}$ & $\begin{array}{c}\mathbf{\uparrow} \\
\text { Apoio } \\
\text { (Princípios de } \\
\text { base) } \\
\text { P.arg.2 }\end{array}$ & $\begin{array}{c}\text { Por isso, } \\
\text { provavelmente }\end{array}$ & $\underset{\substack{\text { Restrição } \\
\text { (a menos que }) \\
\text { P.arg.4 }}}{\longrightarrow}$ & $\begin{array}{c}\text { Conclusão } \\
\text { (Nova tese) } \\
\text { P.arg.3 }\end{array}$ \\
\hline
\end{tabular}

Fonte: Adam (2008, p. 234)

Em termos de ação argumentativa o que se visa é intervir nas opiniões, atitudes ou comportamentos do interlocutor ou auditório (ADAM, 1992). O esquema prototípico desta ação prevê uma combinação formada na relação dado-conclusão, evidenciando um processo em dois movimentos:

Demonstrar-justificar uma tese e refutar uma tese ou certos argumentos de uma tese adversa. Nos dois casos, o movimento é o mesmo, pois se trata de partir de premissas (dados, fatos) que não se poderia admitir sem admitir também esta ou aquela conclusão-asserção (C). Entre os dois, a passagem está garantida pelos procedimentos argumentativos que tomam a forma de encadeamentos de argumentos-provas que correspondem aos suportes de uma lei de passagem ou a microcadeias de argumentos, ou movimentos argumentativos encaixados. (ADAM, 1992, p. 232, grifos do autor)
Segundo Adam (1992), o processo arranja-se a partir de uma unidade de base (dado-conclusão) e o movimento (lei de passagem ou licença para inferir) com que se garante essa relação advém de procedimentos argumentativos (espaço das justificativas: encadeamento de argumentos-provas, microcadeias de argumentos ou movimentos argumentativos encaixados), valendo, na mesma medida para a refutação, caso em que a tese que está sendo defendida (ou tese anterior) pode sofrer restrições.

\section{UM CASO ILUSTRATIVO}

A versão apresentada deste texto foi publicada pelo jornal O Globo no dia 23 de outubro de 2000, segundo aquela edição, tratava-se de um texto transcrito por Kleuber Matta, já que originalmente o texto teria sido pronunciado oralmente. 
Como bem ressalta Cristovam, o fato de o debatedor (chamaremos de enunciador I - E1) traçar a ótica através da qual ele deveria proferir sua resposta criou um relevo curioso, no sentido de condicionar a resposta, o raciocínio. Então, a partir daí, o locutor
(Cristovam Buarque, que chamaremos de enunciador 2-E2), aceitando a condição com que deveria responder à pergunta, segue argumentando de modo a não perder de vista a proposta feita (responder como humanista e não como brasileiro). Segue o texto:

\section{O MUNDO PARA TODOS \\ Cristovam Buarque \\ O Globo, Opinião, 23/10/2000}

[1] Durante debate recente, nos Estados Unidos, fui questionado sobre o que pensava da internacionalização da Amazônia. O jovem introduziu sua pergunta dizendo que esperava a resposta de um humanista e não de um brasileiro. Foi a primeira vez que um debatedor determinou a ótica humanista como o ponto de partida para uma resposta minha.

[2] De fato, como brasileiro eu simplesmente falaria contra a internacionalização da Amazônia. Por mais que nossos governos não tenham o devido cuidado com esse patrimônio, ele é nosso. Respondi que, como humanista, sentindo o risco da degradação ambiental que sofre a Amazônia, podia imaginar a sua internacionalização, como também de tudo o mais que tem importância para a Humanidade. Se a Amazônia, sob uma ótica humanista, deve ser internacionalizada, internacionalizemos também as reservas de petróleo do mundo inteiro. O petróleo é tão importante para o bem-estar da humanidade quanto a Amazônia para o nosso futuro. Apesar disso, os donos das reservas sentem-se no direito de aumentar ou diminuir a extração de petróleo e subir ou não o seu preço. Os ricos do mundo, no direito de queimar esse imenso patrimônio da Humanidade.

[3] Da mesma forma, o capital financeiro dos países ricos deveria ser internacionalizado. Se a Amazônia é uma reserva para todos os seres humanos, ela não pode ser queimada pela vontade de um dono, ou de um país. Queimar a Amazônia é tão grave quanto o desemprego provocado pelas decisões arbitrárias dos especuladores globais. Não podemos deixar que as reservas financeiras sirvam para queimar países inteiros na volúpia da especulação.

[4] Antes mesmo da Amazônia, eu gostaria de ver a internacionalização de todos os grandes museus do mundo. O Louvre não deve pertencer apenas à França. Cada museu do mundo é guardião das mais belas peças produzidas pelo gênio humano. Não se pode deixar que esse patrimônio cultural, como o patrimônio natural amazônico, seja manipulado e destruído pelo gosto de um proprietário ou de um país. Não faz muito, um milionário japonês decidiu enterrar com ele um quadro de um grande mestre. Antes disso, aquele quadro deveria ter sido internacionalizado. 
[5] Durante o encontro em que recebi a pergunta, as Nações Unidas reuniam o Fórum do Milênio, mas alguns presidentes de países tiveram dificuldades em comparecer por constrangimentos na fronteira dos EUA. Por isso, eu disse que Nova York, como sede das Nações Unidas, deveria ser internacionalizada. Pelo menos Manhattan deveria pertencer a toda a Humanidade. Assim como Paris, Veneza, Roma, Londres, Rio de Janeiro, Brasília, Recife, cada cidade, com sua beleza específica, sua história do mundo, deveria pertencer ao mundo inteiro.

[6] Se os EUA querem internacionalizar a Amazônia, pelo risco de deixá-la nas mãos de brasileiros, internacionalizemos todos os arsenais nucleares dos EUA. Até porque eles já demonstraram que são capazes de usar essas armas, provocando uma destruição milhares de vezes maior do que as lamentáveis queimadas feitas nas florestas do Brasil. Nos seus debates, os atuais candidatos à presidência dos EUA têm defendido a ideia de internacionalizar as reservas florestais do mundo em troca da dívida. Comecemos usando essa dívida para garantir que cada criança do mundo tenha possibilidade de ir à escola. Internacionalizemos as crianças tratando-as, todas elas, não importando o país onde nasceram, como patrimônio que merece cuidados do mundo inteiro. Ainda mais do que merece a Amazônia.

[7] Quando os dirigentes tratarem as crianças pobres do mundo como um patrimônio da Humanidade, eles não deixarão que elas trabalhem quando deveriam estudar; que morram quando deveriam viver. Como humanista, aceito defender a internacionalização do mundo. Mas, enquanto o mundo me tratar como brasileiro, lutarei para que a Amazônia seja nossa. Só nossa.

Deste texto, gostaríamos de destacar que a voz que questiona Cristovam Buarque representa a voz de um grupo para o qual a Amazônia deve ser internacionalizada por duas razões principais: por se tratar da maior área verde biodiversificada do planeta e por não ser preservada pelo governo brasileiro com o cuidado e a legislação necessário.

Consideramos que um dos pontos-chave para o debate é perspectivar um ponto de vista controverso, questão essencial para a construção argumentativa do texto. A solicitação por parte de Ei de que a resposta seja enunciada por um ponto de vista específico (humanista e não brasileiro) consubstancia um acordo, ao qual E2, dialogicamente, acolhe em seu discurso.

Interessante observar que, neste caso, há um cenário predefinido para o debate, qual seja: o de que Cristovam assumir a voz de uma humanista e não de sua situação nata de brasileiro. A proposta de que E2 argumente segundo um humanista, previne que argumentação recaia explicitamente sobre a defesa do ponto de vista brasileiro como bem mostra o enunciado: "De fato, como brasileiro eu simplesmente falaria contra a internacionalização da Amazônia.”.

Podemos considerar que a voz que aponta para a conveniência em se 
internacionalizar a Amazônia está subjacente à proposta de E1 que questiona E2, delineia uma tese anterior, sobre a qual E2 precisa contra-argumentar. Tomando o enunciado (inferido) que representa o ponto de vista de que a Amazônia deve ser internacionalizada, podemos sugerir a seguinte representação:

Figura 3 - esquema representativo da perspectiva enunciativa de E1 - a favor da internacionalização da Amazônia

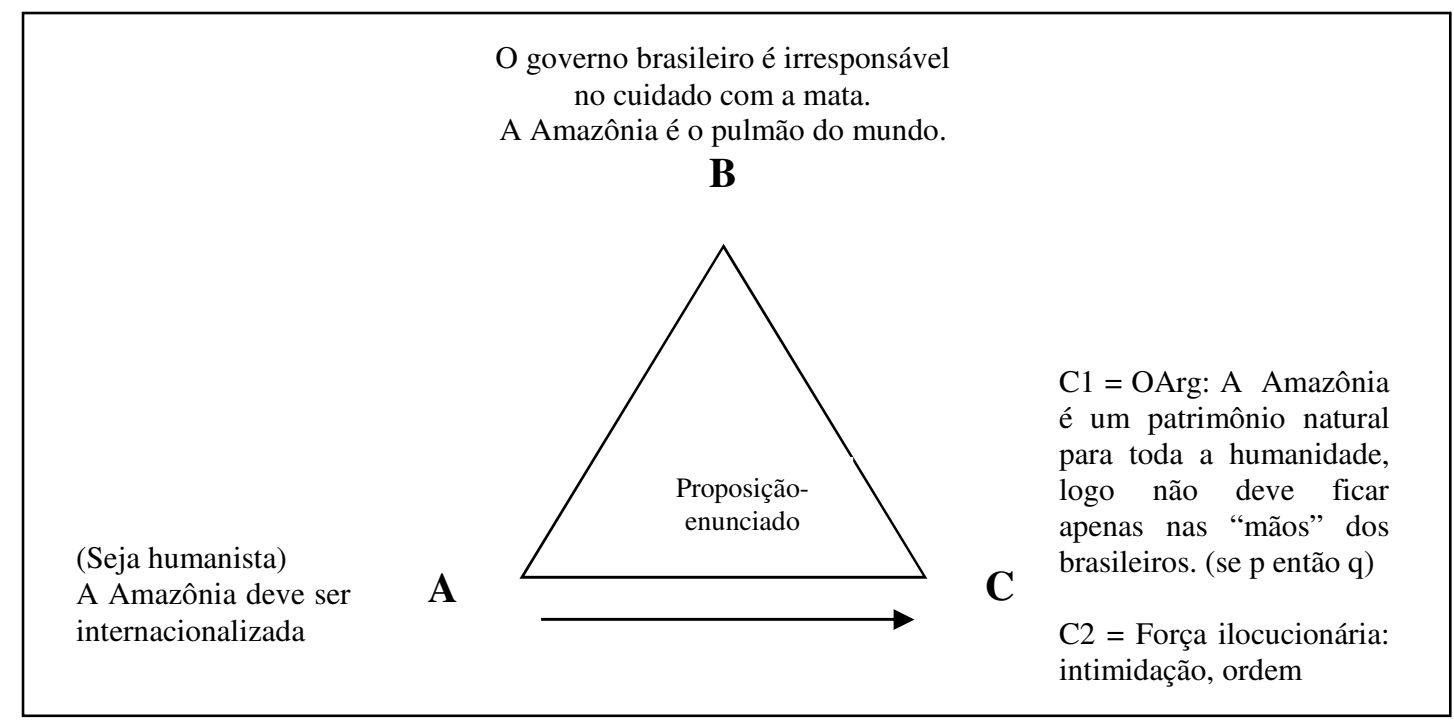

baseado em ADAM, 2008, p. 111

Já [E2] enuncia, através de uma rede articulada de proposições-enunciados, o ponto de vista a respeito da internacionalização da Amazônia, supondo-se humanista, numa contra-argumentação.

Observando o que se apresenta no discurso de E2, vemos que a defesa é para que a Amazônia seja nossa. O percurso pelo qual se chega a esta defesa, no entanto, não é tão direta como imaginaria E1, porquanto se tece uma rede de contra-argumentos em relação à tese de que a Amazônia precisa ser internacionalizada. Assim, faz-se presente no texto um conjunto de sequencias argumentativas que formam a resposta de E2, fugindo do previsível (de que, como brasileiro, certamente E2 diria que a Amazônia é nossa).

Os argumentos são construídos de modo que se sustente uma relação tensionada entre o ponto de vista humanista e o ponto de vista de ser brasileiro a respeito do tema internacionalização da Amazônia. Destas sequências, destacamos o seguinte enunciado-argumento: "Se a Amazônia, sob uma ótica humanista, deve ser internacionalizada, internacionalizemos também as reservas de petróleo do mundo inteiro".

A construção argumentativa resultante é a de que não se justifica a internacionalização da Amazônia pelo ponto de vista de 
que seu "potencial verde" faz parte da humanidade. Se outros patrimônios, também importantes para a humanidade não são internacionalizados, portanto, nessa configuração, o que respalda a internacionalização da Amazônia?
Exercitando uma vez mais a aplicabilidade do que propõe Adam (2008), propomos uma visualização do segmento acima, tecendo, assim, a seguinte disposição:

Figura 4 - esquema representativo da perspectiva enunciativa de E2

\begin{tabular}{|l|l|}
\hline & $\begin{array}{c}\text { PdV-E2 } \\
\text { A Amazônia não é o único bem } \\
\text { universal. }\end{array}$ \\
"Como humanista aceito \\
defender a internacionalização \\
do mundo. Mas, enquanto o \\
mundo me tratar como \\
brasileiro, lutarei para que a \\
Amazônia seja nossa. Só A
\end{tabular}

baseado em ADAM, 2008, p. 111

Observemos que a orientação argumentativa de E1 refuta a orientação argumentativa de E2. Ambos constroem o mesmo esquema lógico (se p então q), o que não significa que as orientações argumentativas, fator este que leva à identificação de representações discursivas particulares para cada enunciador, sejam pautados por pontos de vista opostos sobre o mesmo problema.

O locutor que responde à questão (E2) reconhece as condições com que deve se pronunciar a respeito da internacionalização da Amazônia. Além disso, percebe a lógica embutida na pergunta e a usa em favor da construção de seus argumentos. Interessante observar, também, que E2 se propõe a construir, através das sequências argumentativas, a refutação da condição imposta na pergunta, ou seja, ele (o povo) enquanto brasileiro, não usufrui de nenhum benefício que tenha sido destinado pela mesma lógica com a qual ele teve que raciocinar sobre a internacionalização da Amazônia e assim ele conclui: "Mas enquanto o mundo me tratar como brasileiro, lutarei para que a Amazônia seja nossa. Só nossa."

Até o momento consideramos apenas alguns enunciados, mas devemos esclarecer que uma análise textual se constrói a partir de redes de conexão entre 
proposições-enunciados e aí, torna-se necessário considerar outro princípio orientador: o de que "passamos da série de proposições-enunciados ao seu agrupamento semântico em unidades textuais de níveis crescentes de complexidade" (ADAM, 2008, p. 203). Segundo o autor, é neste nível que a linguística textual se dissocia da gramática transfrasal, uma vez que o todo textual é muito mais que uma combinatória seriada e depende de configurações mais complexas das unidades. Ainda, segundo Adam:

As sequências são unidades textuais complexas, compostas de um número limitado de conjuntos de proposiçõesenunciados: as macroproposições. A macroproposição é uma espécie de período cuja propriedade principal é a de ser uma unidade ligada a outras macroproposições, ocupando posições precisas dentro do todo ordenado das sequencias. Cada macroproposição adquire seu sentido em relação às outras, na unidade hierárquica complexa da sequencia. Nesse aspecto, uma sequência é uma estrutura, isto é:

- Uma rede relacional hierárquica: uma grandeza analisável em partes ligadas entre si e ligadas ao todo que elas constituem.

- Uma entidade relativamente autônoma, dotada de uma organização interna que lhe é própria, e, portanto numa relação de dependência-independência com o conjunto mais amplo do qual faz parte (o texto). (ADAM, 2008, p. 204. Grifos do autor)
A concepção de sequência apresentada por Adam considera ainda que, conforme a combinação com a qual se estruturam as macroproposições se obtém formatações que podem ser narrativas, argumentativas, explicativas, dialogais e descritivas organizadas de modo tipificado, ou seja, hierarquicamente organizadas.

À medida que identificamos a premissa de que a Amazônia deve ser considerada um bem universal e, por isso, deve ser internacionalizada, observamos que o discurso de $\mathrm{E} 2$ contra-argumenta, tendo como suporte um princípio de equidade sobre a importância da Amazônia e outros bens da humanidade. O que se compõe aí é um movimento tipicamente argumentativo, ou seja, há um conjunto de justificativas que sustenta a tese, então, defendida por Cristovam Buarque (E2), que parte de uma tese anterior cujo princípio de base é a importância universal da Amazônia.

Consideremos o seguinte argumento: "De fato, como brasileiro eu simplesmente falaria contra a internacionalização da Amazônia. Por mais que nossos governos não tenham o devido cuidado com esse patrimônio, ele é nosso. Respondi que, como humanista, sentindo o risco da degradação ambiental que sofre a Amazônia, podia imaginar a sua internacionalização, como também de tudo o mais que tem importância para a Humanidade."

Se aplicarmos ao texto um esquema com base em Adam (2008), podemos ter a seguinte configuração: 
Figura 5 - esquema argumentativo com base no texto "O mundo para todos"

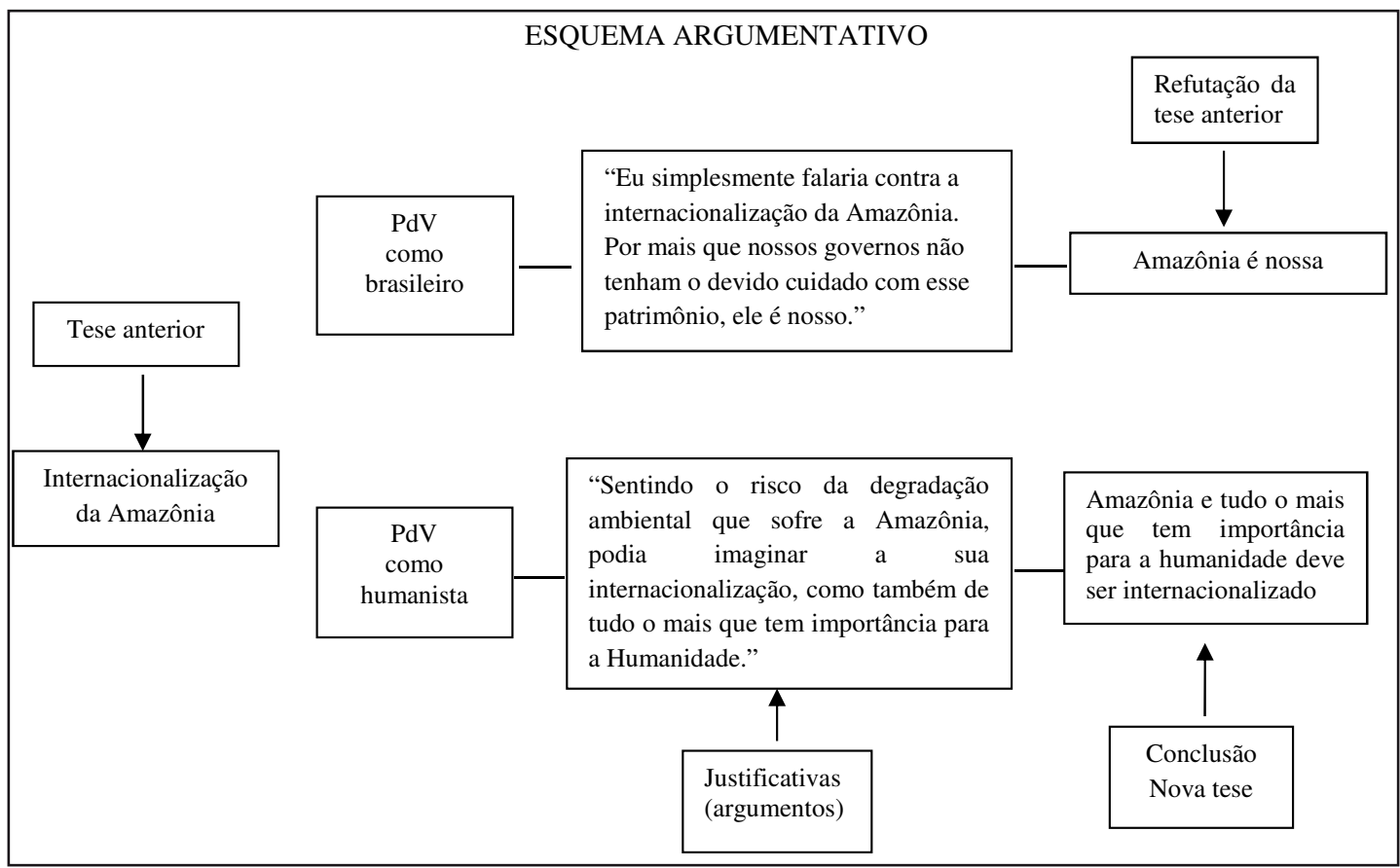

Podemos entender que um arranjo assim composto caracteriza uma macroproposição, constituída por proposições argumentativas.

Na composição acima, entendemos que o locutor exercita dois raciocínios. O primeiro assumindo a posição de brasileiro e a outra como humanista. Aceitando a condição do questionador (E1), o locutor (E2) fideliza-se com a proposta e atrai a atenção para sua argumentação.

Esse procedimento cria uma padrão na forma de construir o argumento a partir do raciocínio: internacionalizar a Amazônia desde que se internacionalizem também outros patrimônios importantes para a humanidade (reserva de petróleo, capital financeiro, grandes museus do mundo, cidades históricas, arsenais nucleares, crianças pobres do mundo). Os argumentos assim apresentados são pautados em valor hipotético, através do qual se deduz que o mundo não está nem politicamente nem eticamente preparado para tratar da internacionalização da Amazônia. Assim, o argumento final (de que o mundo o trata como brasileiro e por isso ele defenda que a Amazônia seja nossa) introduz uma nova realidade, ou seja, se antes o posto era de que o mundo precisa da Amazônia, com a rede de argumentos exposta no texto, a cada parágrafo, fica legitimado que o mundo precisa da Amazônia e muito mais.

\section{Plano De TEXTO}

As sequências argumentativas do texto têm um relevo mais ou menos semelhante, ou seja, é possível verificar que a sequência 
que estrutura boa parte dos períodos corresponde a orações que combinam o SE (hipotético) A então B (condicionamentos) Ainda que cada uma delas mereça um tratamento mais cuidadoso e pormenorizado, optamos, por uma questão de espaço, resumir num plano de texto a constituição argumentativa do texto.

Figura 6 - esquema do plano de texto de "O mundo para todos"

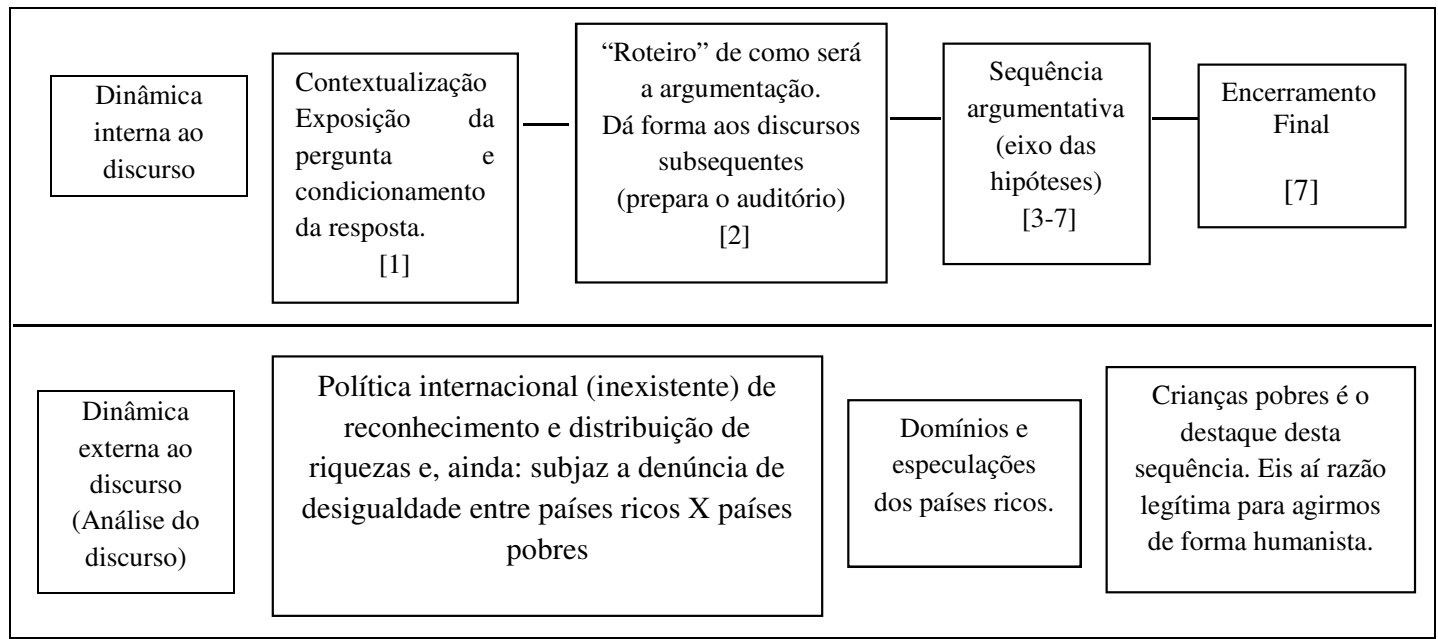

Reforçando o foco a sobre construção discursiva do texto, podemos salientar que o discurso contém modalizações estabelecidas pelo futuro do pretérito. Esta modalização não deixa de estar relacionada com o universo de sentido e certamente indica um ponto de vista do locutor. Ainda mais, indica a responsabilidade enunciativa derivada do acordo que se estabelece na abertura do debate.

A título de exemplificação destacamos alguns modalizadores:

Tabela I - exemplos de modalizadores presentes em "O mundo para todos"

\begin{tabular}{l|l|l}
\multicolumn{1}{c|}{ ENUNCIADOS } & \multicolumn{1}{|c}{ OArg } & Responsabilidade enunciativa \\
\hline $\begin{array}{l}\text { "SE a Amazônia, sob uma } \\
\text { ótica humanista, deve } \\
\text { ser internacionalizada, } \\
\text { internacionalizemos também as } \\
\text { reservas de petróleo do mundo } \\
\text { inteiro." }\end{array}$ & $\begin{array}{l}\text { SE com valor condicionador } \\
\text { (está dentro da proposta } \\
\text { hipotética sugerida pelo } \\
\text { "SE os EUA querem }\end{array}$ & $\begin{array}{l}\text { Posto como condição, o ônus } \\
\text { da responsabilidade de pensar } \\
\text { como humanista retorna para } \\
\text { internacionalizar a Amazônionador (e a voz que ele } \\
\text { pelo risco de deixá-la } \\
\text { nas mãos de brasileiros, } \\
\text { internacionalizemos } \\
\text { arsenais nucleares dos EUA." }\end{array}$ \\
\hline
\end{tabular}


Tabela 1 - exemplos de modalizadores presentes em "O mundo para todos"

conclusão

\begin{tabular}{l|l|l}
\hline \multicolumn{1}{c|}{ ENUNCIADOS } & \multicolumn{1}{c|}{ OArg } & Responsabilidade enunciativa \\
\hline $\begin{array}{l}\text { "DA MESMA FORMA, o capital } \\
\text { financeiro dos países ricos } \\
\text { deveria ser internacionalizado." }\end{array}$ & $\begin{array}{l}\text { Na sequência enumerada de } \\
\text { bens universais, o conectivo DA } \\
\text { MESMA FORMA demonstra } \\
\text { que tanto um como outro item } \\
\text { da enumeração devem receber } \\
\text { o mesmo tratamento }\end{array}$ & $\begin{array}{l}\text { Há uma refutação da ideia } \\
\text { de que a Amazônia é o único } \\
\text { patrimônio que merece uma } \\
\text { discussão a cerca do processo } \\
\text { de internacionalização. }\end{array}$ \\
\hline $\begin{array}{l}\text { Amazônia, eu gostaria de ver a } \\
\text { internacionalização de todos os } \\
\text { grandes museus do mundo." }\end{array}$ & $\begin{array}{l}\text { Antes de uma discussão sobre a } \\
\text { Amazônia, na visão do locutor, } \\
\text { os museus já poderiam ter sido } \\
\text { alvo de internacionalização }\end{array}$ & $\begin{array}{l}\text { O locutor sugere que há } \\
\text { quegligência quanto ao valor } \\
\text { representam para a } \\
\text { humanidade }\end{array}$ \\
\hline "DEVERIA" & $\begin{array}{l}\text { Aponta para a } \\
\text { responsabilidade de países } \\
\text { que devem à humanidade } \\
\text { a internacionalização de } \\
\text { patrimônios mais importantes } \\
\text { para o bem comum }\end{array}$ & $\begin{array}{l}\text { Embora o locutor queira } \\
\text { chamar a atenção (além de } \\
\text { embutir uma crítica), mantém- } \\
\text { se distanciado }\end{array}$ \\
\hline
\end{tabular}

Esta última exposição tem como propósito ilustrar, a partir do texto em análise, o "processamento enunciativo" do texto que tem como propósito comunicativo, argumentar a respeito da internacionalização da Amazônia.

\section{Conclusão}

Propomos uma pequena análise textual com base nos princípios da representação discursiva e sequência argumentativa.

Evidentemente esses dois aspectos estão inseridos entre outras discussões as quais, em boa parte, revelam uma ordem e uma metodologia com a qual Adam distribui os aspectos teóricos apresentados por ele em sua obra A Linguística Textual: introdução à análise textual dos discursos (2208). O autor parte de uma discussão que remonta a abordagens originárias sobre o valor do texto como objeto de estudo e segue com a delimitação das unidades que devem ser dimensionadas numa análise textual.

Nosso recorte teve como objetivo apresentar dois itens basilares da teoria proposta de Adam e por isso destacamos a noção de proposição-enunciado. Entendemos que, falando de proposição-enunciado evidenciamos que o texto é constituído de unidades organizadas para comporem unidades maiores.

Entendemos que uma organização argumentativa e um ponto de vista sejam elementos que perpassam tanto uma dimensão (o da unidade) quanto outra (dos arranjos das 
unidades em sequencias mais complexas). A proposta de analisar textos de opinião, tendo como aporte teórico as concepções de representação discursiva e (na) sequência argumentativa, permitiu evidenciar a tese de que o aparato textual está indissociavelmente atrelado a questões discursivas.

\section{REFERÊNCIAS}

ADAM, J.M. Les textes: types et prototypesrécit, descirption, argumentation, esplication et dialogue. Paris: Natan, 1992.

A linguística textual: introdução textual dos discursos. São Paulo: Cortez, 2008. - Quadro teórico de uma tipologia sequencial. In: BEZERRA,B. G.; CAVALCANTE,M. M.Gêneros e sequências textuais. Recife: Edupe, 2009. p. 115-132. ; HEIDMANN, U.; MAINGUENEAU, D. Análises textuais e discursivas: metodologia e aplicações. São Paulo: Cortez, 2010.

ANTUNES, I. Análise de textos: fundamentos e práticas. São Paulo: Parábola, 2010.

BONINI, A. A noção de sequência textual na análise pragmático-textual de Jean-Michel Adam. In: MEURER, J. L.; BONINI, A.; ROTHD. M.(Org.).Gêneros, teorias, métodos, debates. São Paulo: Parábola, 2005. p. 208-236.

BRETON, P. A argumentação na comunicação. Bauru (SP): EDUSC, 2003.

BUARQUE, C. O mundo para todos. 0 globo, Rio de Janeiro, 23/10/2000. Opinião

GRIZE, J. B. Logique naturelle et communications. Paris: Presses Universitaires de France, 1996.

PASSEGGI, L. et al. A análise textual dos discursos: para uma teoria da produção co(n) textual de sentido. In: BENTES, A.C.; LEITE,
M.Q. (Org.). Linguística de texto e análise da conversação: panorama das pesquisas no Brasil. São Paulo: Cortez, 2010.p. 262-314.

TOULMIN, S. E. Os usos do argumento. São Paulo: Martins Fontes, 2006.

TRASK, R. L. Dicionário de linguagem e linguística. São Paulo: Contexto. 2011.

SASSERON, L. H.; CARVALHO, A. M. P. Uma análise de referências teóricas sobre a estrutura do argumento para estudos de argumentação no ensino de ciências. Revista Ensaio, Belo Horizonte, v.13, p. 243-262, 2011.

Recebido para publicação em 25 out. 2015 Aceito para publicação em 20 nov. 2015. 